\title{
Mechanism of inactivation of trypsin by antithrombin
}

\author{
Åke DANIELSSON and Ingemar BJÖRK \\ Department of Medical and Physiological Chemistry, Faculty of Veterinary Medicine, \\ Swedish University of Agricultural Sciences, The Biomedical Center, Box 575, S-751 23 Uppsala, Sweden
}

(Received 4 March 1982/Accepted 2 June 1982)

\begin{abstract}
General aspects of the mechanism of antithrombin action were elucidated by a comparison of the inactivation of trypsin by antithrombin with the inactivation of coagulation proteinases by the inhibitor. Bovine antithrombin and bovine trypsin were shown to form an inactive equimolar complex. A non-complexed, proteolytically modified form of antithrombin, electrophoretically identical with that formed in the reaction with coagulation proteinases, was also produced in the reaction with trypsin. In the absence of heparin, the inactivation of trypsin by antithrombin was 20 times faster than the inactivation of thrombin; the second-order rate constant was $1.5 \times 10^{5} \mathrm{M}^{-1} \cdot \mathrm{s}^{-1}$ at $25^{\circ} \mathrm{C}$ and pH 7.4. However, the inhibition of thrombin was accelerated about 30 times more efficiently by small amounts of heparin than was trypsin inhibition. Dissociation of the antithrombin-trypsin complex at $\mathrm{pH} 7.4$ followed first-order kinetics with a halflife for the complex of about $80 \mathrm{~h}$ at $25^{\circ} \mathrm{C}$. The complex was rapidly and quantitatively dissociated at $\mathrm{pH} 11$, resulting in the liberation of a modified two-chain form of the inhibitor, cleaved at the same Arg-Ser bond as in modified antithrombin released from complexes with thrombin, Factor $\mathrm{Xa}$ and Factor IXa. This supports the previous proposal that this bond is the active-site bond of antithrombin. Antisera specific for thrombin-modified antithrombin reacted with purified antithrombin-trypsin complex, indicating that the inhibitor was present in the complex in a form immunologically identical with thrombin-modified antithrombin. The results thus suggest a common mechanism, but different kinetics, for the inhibition of trypsin and coagulation proteinases by antithrombin.
\end{abstract}

Antithrombin neutralizes all serine proteinases of the intrinsic coagulation system by forming stable equimolar complexes with the enzymes [for reviews, see Rosenberg (1977a,b) and Barrowcliffe et al. (1978)]. These reactions are slow in the absence of heparin; the second-order rate constant for the association of bovine antithrombin with thrombin, for example, is about $1 \times 10^{4} \mathrm{M}^{-1} \cdot \mathrm{s}^{-1}$ at $\mathrm{pH} 7.5$ and $37^{\circ} \mathrm{C}$ (Jesty, $1979 \mathrm{~b}$ ). Optimal amounts of heparin accelerate the formation of the complexes up to 2000 -fold (Jordan et al., 1979). The accelerating effect involves binding of heparin to antithrombin, which induces a conformational change of the inhibitor (Rosenberg \& Damus, 1973; Villanueva \& Danishefsky, 1977; Einarsson \& Andersson, 1977; Nordenman \& Björk, 1978; Olson et al., 1981). In addition, binding of heparin to the enzyme contributes to the enhanced rate of inhibition of some coagulation proteinases

Abbreviation used: Bz-Ile-Glu-Gly-Arg-Nan, $N$-benzoyl-L-isoleucyl-L-glutamylglycyl-L-arginine $p$ nitroanilide.
(Laurent et al., 1978; Jordan et al., 1980; Oosta et al., 1981; Holmer et al., 1981).

Dissociation by nucleophilic agents of the complexes between antithrombin and thrombin, Factor $\mathrm{Xa}$ or Factor IXa, produces intact proteinase and a proteolytically modified antithrombin, but no detectable amounts of intact inhibitor (Jesty, 1979a; Fish \& Björk, 1979; Longas \& Finlay, 1980; Björk et al., 1982). The modified antithrombins isolated from the three complexes are all identical and cleaved at a single site, which is between Arg-385 and Ser-386 in human antithrombin, the sequence of which is known (Petersen et al., 1979); an identical site at the homologous position is cleaved in the bovine protein (Jörnvall et al., 1979; Björk et al., 1981, 1982). The same modified inhibitor also dissociates spontaneously from the antithrombinthrombin complex (Danielsson \& Björk, 1980; Griffith \& Lundblad, 1981). Moreover, formation of the complexes between antithrombin and thrombin or Factor $\mathrm{Xa}$ is accompanied by the appearance of a non-complexed modified form of 
antithrombin that is cleaved at the same site as the modified inhibitor released from the complexes (Fish et al., 1979a; Björk et al., 1982). This and other evidence (Carrell et al., 1980) indicates that the observed cleavage site is the active-site bond of antithrombin, i.e. the peptide bond that interacts with the proteinases.

Antithrombin has been shown to interact also with proteinases that are not directly involved in the coagulation cascade, such as plasmin (Highsmith \& Rosenberg, 1973), kallikrein (Rosenberg et al., 1976) and trypsin (Figarella et al., 1974; Learned et al., 1976; Feinman, 1979; Mahoney et al., 1980). However, these reactions have not been well characterized. The aim of the present work was to study the reaction with trypsin in detail to allow a comparison of the mechanisms by which antithrombin inhibits coagulation and non-coagulation proteinases.

\section{Materials and methods}

Bovine antithrombin was prepared as described by Miller-Andersson et al. (1974). No traces of heparin were detected in the preparation by a method based on comparison of the rates of inactivation of thrombin by the inhibitor in the presence and absence of Polybrene (Jesty, 1979b). Bovine $a$ thrombin was prepared from prethrombin 1 by published procedures (Owen et al., 1974; Lundblad et al., 1975; Carlström et al., 1977). Thrombinmodified antithrombin and antithrombin-thrombin complex were purified by methods described previously (Fish et al., 1979a; Danielsson \& Björk, 1980).

Trypsin (twice-crystallized) from bovine pancreas was obtained from Sigma Chemical Co. (St. Louis, MO, U.S.A.). Two methods were used for further purification. In the first of these, trypsin was applied to a column containing 4 -aminobenzamidine bound to succinylated aminododecyl-cellulose (E. Merck, Darmstadt, Germany). The column was washed with $0.1 \mathrm{M}$-sodium acetate, $0.1 \mathrm{M}-\mathrm{NaCl}$, $1 \mathrm{mM}-\mathrm{CaCl}_{2}, \mathrm{pH} 5.5$, and $\beta$-trypsin was eluted with $0.1 \mathrm{M}$-glycine $/ \mathrm{HCl} / 0.1 \mathrm{M}-\mathrm{NaCl} / 1 \mathrm{~mm}-\mathrm{CaCl}_{2}, \mathrm{pH} 2.0$. The preparation was $70 \%$ active, as determined by active-site titration with $p$-nitrophenyl $p$-guanidinobenzoate (Chase \& Shaw, 1970). The second method was chromatography on soya-bean-trypsin-inhibitorsubstituted Sepharose (Yung \& Trowbridge. 1975: Robinson et al., 1971), which yielded 90\% active $\beta$-trypsin. The latter preparation was used in most experiments.

Antithrombin-trypsin complex was purified by two methods. Attempts to purify the complex in its native state were done by mixing $18 \mathrm{mg}$ of antithrombin with $2.7 \mathrm{mg}$ of trypsin in the presence of $1 \mathrm{mM}$-benzamidine hydrochloride for $30 \mathrm{~s}$ at $+4^{\circ} \mathrm{C}$.
Phenylmethanesulphonyl fluoride was then added to $0.2 \mathrm{mM}$, and the sample was applied at $+4^{\circ} \mathrm{C}$ to a heparin-agarose column $(1.6 \mathrm{~cm} \times 13 \mathrm{~cm})$. The column was washed with $0.05 \mathrm{M}-\mathrm{Tris} / \mathrm{HCl} / 0.1 \mathrm{M}$ $\mathrm{NaCl} / 0.1 \mathrm{~mm}$-phenylmethanesulphonyl fluoride, pH 7.4, and the complex was then eluted with a linear gradient (total volume $400 \mathrm{ml}$ ) to $0.8 \mathrm{M}-\mathrm{NaCl}$ in the same buffer. The complex was made $0.2 \mathrm{mM}$ in phenylmethanesulphonyl fluoride and $1 \mathrm{~mm}$ in benzamidine and was stored at $-20^{\circ} \mathrm{C}$. Denatured complex was prepared by incubating $16 \mathrm{mg}$ of antithrombin with $8 \mathrm{mg}$ of trypsin for $60 \mathrm{~s}$ in the presence of $15 \mathrm{mg}$ of unfractionated heparin and $3 \mathrm{~mm}$-benzamidine. Sodium dodecyl sulphate was then added to a final concentration of $1 \%$, and the sample was boiled for $5 \mathrm{~min}$. Subsequent gel chromatography on a Sephacryl S-200 (Pharmacia Fine Chemicals, Uppsala, Sweden) column $(2.6 \mathrm{~cm} \times 90 \mathrm{~cm})$ in $0.02 \mathrm{M}$-sodium phosphate $/ 0.05 \%$ sodium dodecyl sulphate, $\mathrm{pH} 7.2$, gave two peaks. The first of these contained incompletely separated complex and free antithrombin, and the second contained trypsin. Pure antithrombin-trypsin complex was obtained by pooling the material in the front half of the first peak.

Modified antithrombin was released from the purified denatured antithrombin-trypsin complex by exposure of the complex $(21 \mathrm{mg}$ in $0.5 \%$ sodium dodecyl sulphate) to $\mathrm{pH} 11.5$ for $30 \mathrm{~min}$. The modified inhibitor was then isolated on a Sephacryl S-200 column $(2.6 \mathrm{~cm} \times 90 \mathrm{~cm})$ in $0.02 \mathrm{M}$-sodium phosphate $/ 0.05 \%$ sodium dodecyl sulphate, $\mathrm{pH}$ 7.2. Reduction and carboxymethylation of modified antithrombin with iodo $\left[1-{ }^{14} \mathrm{C}\right.$ lacetate, separation of the liberated peptide material on Sephacryl S-200 and further treatment of this material were by procedures described previously (Jörnvall et al., 1979; Björk et al., 1982).

Commercial heparin was coupled to $\mathrm{CNBr}$-activated agarose (Nordenman \& Björk, 1978) with a resulting heparin content of $2.2 \mathrm{mg}$ per $\mathrm{ml}$ of wet gel. Heparin with high affinity for antithrombin was prepared as detailed earlier (Danielsson \& Björk, 1981). A fraction with average mol.wt. 13200 and an anticoagulation activity of 207 B.P. (British Pharmacopoeia) units/mg was used.

The stoichiometry of inhibition of trypsin by antithrombin was determined by incubating $9 \mu \mathrm{M}$ trypsin with increasing amounts of inhibitor for $60 \mathrm{~s}$ at $25^{\circ} \mathrm{C}$ in $0.05 \mathrm{M}-\mathrm{Tris} / \mathrm{HCl} / 0.1 \mathrm{M}-\mathrm{NaCl}$, $\mathrm{pH}$ 7.4. The reaction was found to be complete after this time, even at the lowest inhibitor concentration used. For the determination of residual enzyme activity, the sample was diluted 45 -fold with buffer, and $50 \mu \mathrm{l}$ was transferred to a thermostatically controlled cuvette $\left(25^{\circ} \mathrm{C}\right)$ containing $2.15 \mathrm{ml}$ of $0.05 \mathrm{M}$ Tris $/ \mathrm{HCl}$ buffer, pH 8.2 (adjusted to $I 0.15$ with $\mathrm{NaCl}$ ) and $250 \mu \mathrm{l}$ of $1 \mathrm{~mm}-\mathrm{Bz}-\mathrm{Ile}-\mathrm{Glu}-\mathrm{Gly}-\mathrm{Arg}-\mathrm{Nan}$, 
S-2222; AB Kabi, Stockholm, Sweden). The release of $p$-nitroaniline was monitored spectrophotometrically at $405 \mathrm{~nm}$.

The kinetics of the reaction between antithrombin and thrombin or trypsin were analysed under pseudo-first-order conditions, essentially as described by Jesty $(1979 b)$ for the reaction with thrombin. The experiments were carried out at $25^{\circ} \mathrm{C}$ in $0.05 \mathrm{M}$-sodium phosphate $/ 0.1 \%$ poly(ethylene glycol), $\mathrm{pH}$ 7.4. Apart from this modification, the experimental design in the analyses of thrombin inhibition was identical with that used by Jesty $(1979 b)$. In the trypsin experiments, antithrombin concentrations ranged from $90 \mathrm{nM}$ to $895 \mathrm{nM}$, and the trypsin concentration was $10 \mathrm{nM}$ or $2 \mathrm{nM}$. Residual trypsin activity was determined after three to five different incubation times, depending on the reaction rate, by transferring a $100 \mu \mathrm{l}$ sample to a thermostatically controlled cuvette $\left(25^{\circ} \mathrm{C}\right)$, containing $100 \mu \mathrm{l}$ of $2 \mathrm{mM}$-Bz-Ile-Glu-Gly-Arg-Nan and $300 \mu \mathrm{l}$ of buffer. The spectrophotometer tracings of the increase in absorbance were linear in all analyses, which shows that the concentration of the chromogenic substrate was sufficiently high to block all further inhibition.

The effect of heparin on the rate of inhibition of trypsin and thrombin was studied by incubating constant concentrations of antithrombin (61 and $314 \mathrm{nM}$ in experiments with trypsin and thrombin respectively) with different amounts of high-affinity heparin for $2 \mathrm{~min}$. Trypsin or thrombin was then added to final concentrations of 7 and $48 \mathrm{~nm}$ respectively, and remaining free enzyme was assayed after different times at $25^{\circ} \mathrm{C}$ by addition of trypsin samples to Bz-Ile-Glu-Gly-Arg-Nan in $0.05 \mathrm{M}$ sodium phosphate $/ 0.1 \%$ poly(ethylene glycol), $\mathrm{pH} 7.4$, or thrombin samples to D-phenylalanyl-Lpipecolyl-L-arginine $p$-nitroanilide (S-2238; AB $\mathrm{Kabi}$ ) in the same buffer. The enzyme assays were done at $25^{\circ} \mathrm{C}$ with final substrate concentrations of $0.4 \mathrm{~mm}$.

Measurements of the rate of dissociation of the antithrombin-trypsin complex were based on the method described by Jesty $(1979 b)$ for the antithrombin-thrombin complex. The experiments were carried out at $25^{\circ} \mathrm{C}$ in $0.05 \mathrm{M}$-sodium phosphate/ $0.1 \%$ poly (ethylene glycol), $\mathrm{pH} 7.4$. Trypsin, $0.7 \mu \mathrm{M}$ (active-site concentration), was incubated for $5 \mathrm{~min}$ with $1.7 \mu \mathrm{M}$-antithrombin; after this time the inhibition was complete. Samples $(25-250 \mu l)$ were then transferred to a cuvette containing Bz-Ile-Glu-GlyArg-Nan ( $1.14 \mathrm{~mm}$ final concn. in $700 \mu \mathrm{l}$ of buffer), and the parabolic increase in absorbance caused by release of active enzyme from the complex was recorded for $15 \mathrm{~min}$. The curves were analysed as described by Jesty $(1979 b)$. This method is valid only if the reverse reaction, i.e. complex-formation between the excess antithrombin and the liberated trypsin, is blocked in the cuvette. This was achieved by the use of a concentration of the chromogenic substrate about 50 times the $K_{\mathrm{m}}$ value; essentially all the free trypsin should thus be present as enzymesubstrate complex. The validity of this arrangement is shown by the fact that, in the analyses of the association kinetics (done at a lower substrate concentration), the inhibition reaction stopped immediately after the antithrombin-trypsin mixture was added to the substrate solution, even at the highest inhibitor concentration used (see above).

$N$-Terminal sequence analyses were done with the dimethylaminoazobenzene isothiocyanate/phenyl isothiocyanate double-coupling method (Chang et al., 1978). Amino acid derivatives were separated on polyamide sheets in two solvent systems, and the results were evaluated as described by von BahrLindström et al. (1982).

Sodium dodecyl sulphate/polyacrylamide-gel electrophoresis was done by the method developed by Weber \& Osborn (1969). Immunodiffusion was performed on glass plates in $1 \%$ agarose gels containing $0.05 \mathrm{M}-\mathrm{Tris} / \mathrm{HCl} / 0.1 \mathrm{M}-\mathrm{NaCl}, \mathrm{pH} 7.4$. Antisera against thrombin-modified antithrombin, absorbed with native antithrombin, were used (Wallgren et al., 1981).

Protein concentrations were measured spectrophotometrically at $280 \mathrm{~nm}$. The specific absorption coefficients used for bovine antithrombin, bovine trypsin, bovine thrombin, antithrombin-trypsin complex and antithrombin-thrombin complex were 0.67 (Nordenman et al., 1977), 1.54 (Robinson et al., 1971), 1.75 (Fish et al., 1979a), 0.93 and 1.10 litre $\cdot \mathrm{g}^{-1} \cdot \mathrm{cm}^{-1}$ respectively. The two last values were calculated from the weight fractions and the absorption coefficients of the two proteins comprising each complex. In experiments critically dependent on the amount of active trypsin (i.e. in analyses of the stoichiometry and dissociation kinetics of the antithrombin-trypsin complex), enzyme concentrations were expressed as active-site concentrations.

\section{Results}

\section{Electrophoretic analysis of the antithrombin-trypsin reaction}

A qualitative characterization of the reaction between antithrombin and trypsin was done by incubating equimolar amounts of the two proteins for $60 \mathrm{~s}$ in the presence of the reversible trypsin inhibitor benzamidine (included to decrease secondary proteolytic degradation; see below). The reaction products were analysed by dodecyl sulphate/polyacrylamide-gel electrophoresis under reducing conditions (Fig. 1, gel 1). The major product corresponded to an antithrombin-trypsin complex with apparent mol.wt. of 80000 . The band that migrated slightly faster than this form of the complex most 


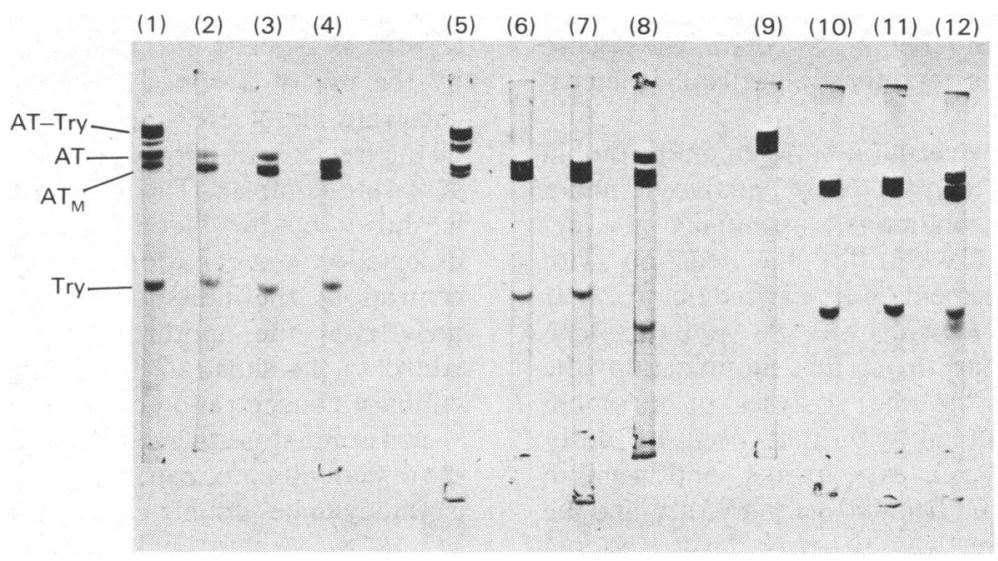

Fig. 1. Analyses, by dodecyl sulphate/polyacrylamide-gel electrophoresis under reducing conditions, of the dissociation of antithrombin-trypsin complex prepared in different ways

(1) An equimolar mixture of antithrombin and trypsin $(9 \mu \mathrm{M})$, incubated for $60 \mathrm{~s}$ in the presence of $1 \mathrm{~mm}$-benzamidine; (2) the material in (1), kept at $\mathrm{pH} 11$ for $2 \mathrm{~h}$; (3) as in (2), with thrombin-modified antithrombin added; (4) as in (2), with native antithrombin added; (5) antithrombin-trypsin complex, purified in its native state; (6) the material in (5), kept at $\mathrm{pH} 11$ for $2 \mathrm{~h}$; (7) as in (6), with thrombin-modified antithrombin added; (8) as in (6), with native antithrombin added; (9) antithrombin-trypsin complex, purified in its denatured state; (10) the material in (9), kept at $\mathrm{pH} 11.5$ for $30 \mathrm{~min}$; (11) as in (10), with thrombin-modified antithrombin added; (12) as in (10), with native antithrombin added; All samples were boiled for $60 \mathrm{~s}$ in $1 \%(\mathrm{w} / \mathrm{v})$ sodium dodecyl sulphate $/ 0.1 \mathrm{M}$ - $\beta$-mercaptoethanol, pH 7.0, before analyses. Abbreviations used: AT-Try, antithrombin-trypsin complex; AT, intact antithrombin; $\mathrm{AT}_{\mathrm{M}}$, modified antithrombin; Try, trypsin.

likely represents complex which has been partly degraded by free enzyme. Similar degraded forms of inhibitor-enzyme complexes appear when antithrombin and either thrombin or Factor $\mathrm{Xa}$ react in near-equimolar amounts (Fish et al., 1979b; Jesty, $1979 a$ ). The polypeptide migrating slightly ahead of native antithrombin was found to co-migrate with the large chain of added thrombin-modified antithrombin (mol.wt. 51000). A non-complexed proteolytically modified form of the inhibitor, highly similar to, or identical with, that formed in the reaction between antithrombin and thrombin or Factor $\mathrm{Xa}$ (Fish et al., 1979b; Björk et al., 1982), is thus produced also in the reaction with trypsin. Free antithrombin and trypsin accounted for an appreciable amount of the stained material on the gel, since the reaction was not complete after $60 \mathrm{~s}$ in the presence of $1 \mathrm{~mm}$-benzamidine. Longer incubation times resulted in considerably more proteolytic degradation of the antithrombin-trypsin complex.

In some experiments, the results of which are not shown, benzamidine was omitted. This resulted in rapid degradation of the intact complex. In addition, a new non-complexed modified antithrombin species, which migrated faster than the large chain of the thrombin-modified inhibitor under reducing conditions, i.e. with apparent mol.wt. 48000 , appeared on the gels. In a control experiment, purified throm- bin-modified antithrombin was quantitatively converted by small amounts of trypsin into a species which co-migrated with this new modified form of the inhibitor. The latter thus apparently is a secondary degradation product derived from the modified inhibitor formed initially.

In the reaction of antithrombin with thrombin or Factor $\mathrm{Xa}$, the production of the free modified antithrombin increases markedly in the presence of high-affinity heparin (Björk et al., 1982; Björk \& Fish, 1982). However, the amount of trypsinmodified inhibitor remained essentially constant when antithrombin and trypsin were mixed in equimolar amounts, regardless of whether heparin was present or not (results not shown).

\section{Stoichiometry of inhibition}

The band on the polyacrylamide gels corresponding to a polypeptide with apparent mol.wt. 80000 indicated the formation of a 1:1 complex between antithrombin and trypsin. The same molecular weight and apparent stoichiometry was reported previously for the complex between human antithrombin and porcine trypsin (Mahoney et al., 1980). The stoichiometry was confirmed by titrations of a fixed amount of trypsin with increasing amounts of inhibitor. However, somewhat more than an equimolar amount of antithrombin, 1.3 
$\mathrm{mol} / \mathrm{mol}$ of active trypsin, was required to abolish enzyme activity completely in these analyses. This is probably due to the production of inactive modified antithrombin concomitant with complexformation, as demonstrated above; the same phenomenon has been noted in titrations of antithrombin with thrombin in the presence of heparin (Björk \& Fish, 1982).

\section{Kinetics of formation and dissociation of the anti- thrombin-trypsin complex}

The rates of formation of the complexes between antithrombin and trypsin or thrombin were studied under pseudo-first-order conditions at $25^{\circ} \mathrm{C}$. The formation of some modified antithrombin concurrent with the complexes should not have influenced these analyses, since antithrombin was present in a large excess. All plots of $\ln$ (enzyme activity) against incubation time were linear for both reactions, indicating that pseudo-first-order conditions were fulfilled. Second-order rate constants of $1.5 \times 10^{5} \mathrm{M}^{-1} \cdot \mathrm{s}^{-1}$ for trypsin and $7.3 \times 10^{3} \mathrm{M}^{-1} \cdot \mathrm{s}^{-1}$ for thrombin were calculated from plots of the observed pseudo-first-order rate constants against antithrombin concentration (Fig. 2). Trypsin thus is neutralized by antithrombin about 20 times more rapidly than thrombin. When the difference in temperature is considered, the rate constant for the reaction with thrombin is in good agreement with the value obtained by Jesty $(1979 b)$ at $37^{\circ} \mathrm{C}$ and $\mathrm{pH} 7.5$, namely $1.43 \times 10^{4} \mathrm{M}^{-1} \cdot \mathrm{s}^{-1}$. However, in a preliminary communication, Feinman (1979) reported a slightly higher rate constant for the inhibition of trypsin $\left(2.7 \times 10^{5} \mathrm{M}^{-1} \cdot \mathrm{s}^{-1}\right)$, obtained by stopped-flow measurements. The rate by which antithrombin inhibits trypsin is comparable with the rate by which $\alpha_{1}$-proteinase inhibitor inactivates the enzyme; the second-order rate constant for the latter reaction has been reported to be $1.3 \times 10^{5} \mathrm{M}^{-1}$. $\mathrm{s}^{-1}$ at $\mathrm{pH} 8.0,25^{\circ} \mathrm{C}$ (Beatty et al., 1980).
The dissociation rate of the antithrombin-trypsin complex was analysed by continuously monitoring the release of active enzyme. The complex was formed at an excess of inhibitor over enzyme in order to limit proteolytic degradation. The first-order rate constant for dissociation of the complex at $25^{\circ} \mathrm{C}$ was found to be independent of complex concentration in the range $25-250 \mathrm{~nm}$ and was calculated to be $(2.45 \pm 0.16) \times 10^{-6} \mathrm{~s}^{-1}$ (S.D., $\left.n=8\right)$. This corresponds to a half-life for the complex of about $80 \mathrm{~h}$. This rate constant should be compared with that of $1.43 \times 10^{-6} \mathrm{~s}^{-1}$ measured for the antithrombinthrombin complex at $37^{\circ} \mathrm{C}$ (Jesty, 1979b). The complex with trypsin thus dissociates somewhat faster than the antithrombin-thrombin complex. The dissociation rate of the antithrombin-trypsin complex was estimated previously from the increase in postburst rate in $p$-nitrophenyl $p$-guanidinobenzoate titrations (Feinman, 1979). An apparent first-order rate constant of $4.0 \times 10^{-4} \mathrm{~s}^{-1}$ was obtained, i.e. a value more than 100 -fold higher than that reported here. Part of the reason for this discrepancy may be that the previous studies were done at an alkaline $\mathrm{pH}$ (presumably 8.3; Chase \& Shaw, 1970), which decreases the stability of the complex (Mahoney et al., 1980).

\section{Effect of heparin on the rate of complex-formation}

The kinetics of inhibition of thrombin and trypsin in the presence of non-stoichiometric amounts of heparin were also analysed under pseudo-first-order conditions, i.e. at an excess of antithrombin over enzyme, but only at one antithrombin concentration for either enzyme. The plots of ln (enzyme activity) against reaction time were linear also in these experiments. Relative rates for the inhibition of the two enzymes in the presence of increasing amounts of heparin were calculated from the observed pseudo-

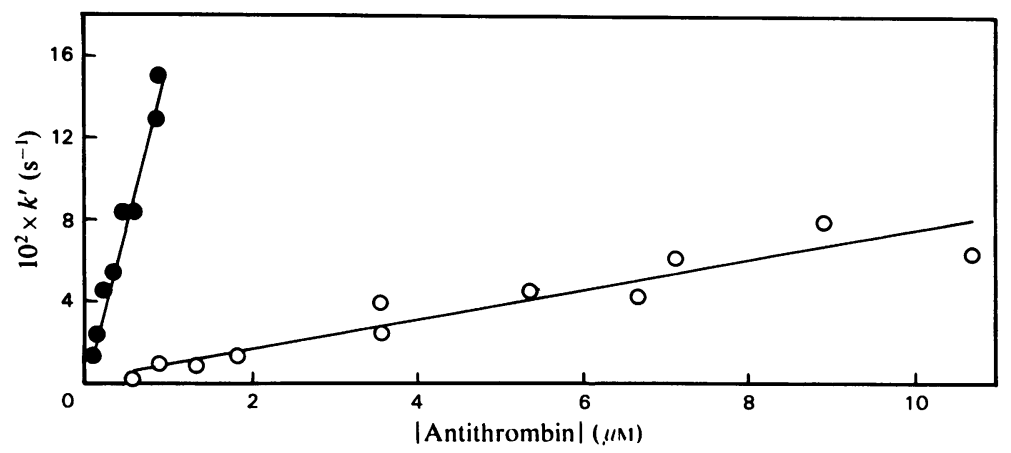

Fig. 2. Kinetics of inhibition of trypsin and thrombin by antithrombin

Pseudo-first-order rate constants $\left(k^{\prime}\right)$, measured with antithrombin in excess, are plotted as a function of antithrombin concentration. Second-order rate constants were calculated from the slopes of these plots. $O$, Trypsin; $O$, thrombin. 
first-order rate constants (Fig. 3). The non-stoichiometric amounts of high-affinity heparin studied accelerated the inactivation of thrombin about 30 times more efficiently than the inhibition of trypsin.

\section{Release of modified antithrombin from the anti- thrombin-trypsin complex}

The products obtained by dissociation of the antithrombin-trypsin complex, prepared in three different ways, were characterized. In the first study, the proteins were mixed and the reaction was stopped as in the electrophoretic analysis of the reaction described above (Fig. 1, gel 1), but no purification of the complex was done. The $\mathrm{pH}$ was then raised to 11 and the mixture was left at room temperature for $2 \mathrm{~h}$. Dodecyl sulphate/polyacrylamide-gel electrophoresis under reducing conditions (Fig. 1, gels 2-4) showed that the disappearance of the complex was accompanied by an increase in the amount of material co-migrating with thrombin-modified antithrombin, whereas the bands corresponding to intact antithrombin and trypsin did not show an increase. Trypsin is, however, poorly stained by Coomassie Blue, and a substantial increase may have escaped detection. Similar results were obtained if, instead, the mixture was boiled for $60 \mathrm{~min}$ in $1 \%$ sodium dodecyl sulphate at $\mathrm{pH} 7.0$ or treated with $1.5 \mathrm{M}-\mathrm{NH}_{3}$, conditions which also dissociate complexes between antithrombin and coagulation proteinases (Fish \& Björk, 1979; Björk et al., 1982).

In a further analysis the dissociation of antithrombin-trypsin complex purified in its native state was studied. In spite of extensive precautions, such

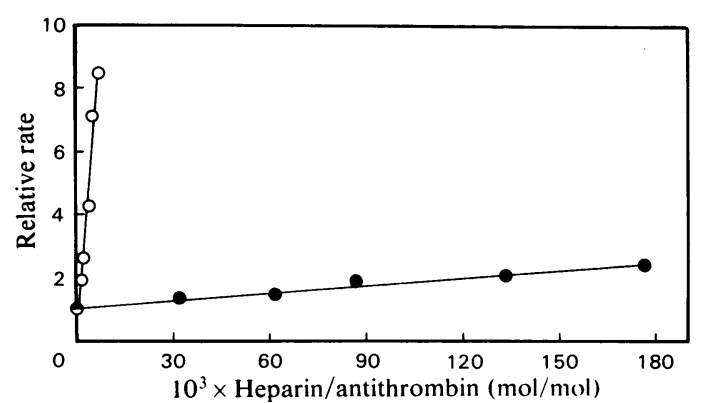

Fig. 3. Kinetics of inhibition of trypsin and thrombin by antithrombin in the presence of heparin

For each enzyme, pseudo-first-order rate constants at different heparin concentrations were measured at a constant antithrombin concentration (which was different for the two enzymes), as in the analyses of the kinetics in the absence of heparin. Relative rates were calculated as the ratios between the pseudofirst-order rate constants measured in the presence and absence of heparin. Trypsin; $O$, thrombin. as the use of an excess of antithrombin and the addition of low-molecular-weight proteinase inhibitors during the purification, proteolytic degradation of the complex was not completely avoided (Fig. 1, gel 5). Nevertheless, like the unpurified complex, the purified native complex released a modified inhibitor, co-migrating with thrombin-modified antithrombin, when it dissociated at pH 11 (Fig. 1, gels 6-8), whereas no intact antithrombin appeared.

The presence of degradation products of the antithrombin-trypsin complex was avoided almost completely by purifying the complex in its denatured state (Fig. 1, gel 9). Again, modified antithrombin, which co-migrated with the thrombin-modified inhibitor in electrophoresis, but no intact inhibitor, was released when the complex was exposed to high pH (Fig. 1, gels 10-12).

The trypsin-modified antithrombin released from the denatured complex was purified and its cleavage site was determined by sequence analysis of the peptide liberated by reduction and subsequently carboxymethylated. Analyses by the dimethylaminoazobenzene isothiocyanate method showed the $N$ terminal sequence:

\section{Ser-Leu-Asn-Ser-Asp-Arg-Val-Thr}

i.e. the same sequence as that of the small fragment from modified antithrombin derived from complexes with thrombin, Factor Xa and Factor IXa (Jörnvall et al., 1979; Björk et al., 1982). No other residues were detected in any step, indicative of a single cleavage site in the modified inhibitor.

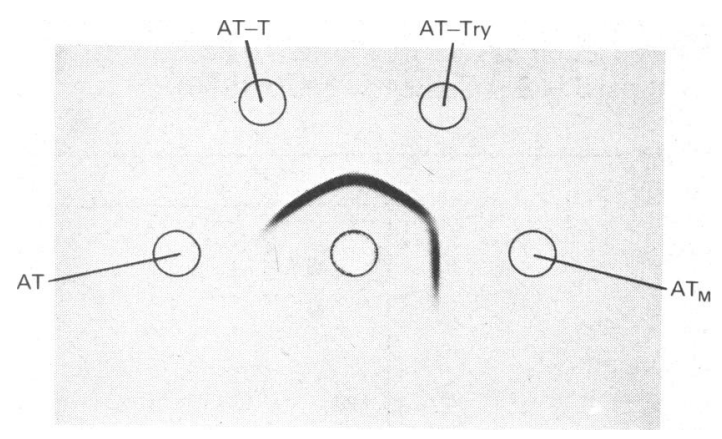

Fig. 4. Immunodiffusion analyses of antithrombin-trypsin complex

An antiserum against thrombin-modified antithrombin, absorbed with intact antithrombin and thus specific for the modified inhibitor, was used. Antigen concentrations were: antithrombin-trypsin complex (AT-Try), $0.6 \mathrm{mg} / \mathrm{ml}$; antithrombinthrombin complex (AT-T), $0.8 \mathrm{mg} / \mathrm{ml}$; native antithrombin (AT) and thrombin-modified antithrombin $\left(\mathrm{AT}_{\mathrm{M}}\right), 0.5 \mathrm{mg} / \mathrm{ml}$. 


\section{Immunodiffusion analysis of the complex}

Antithrombin-trypsin complex, purified without denaturation, was studied by immunodiffusion with antisera against thrombin-modified antithrombin that were specific for the cleavage-induced neoantigenic determinants of the modified inhibitor (Wallgren et al.. 1981). The analyses (Fig. 4) showed a complete immunological identity of antithrombin-trypsin complex with thrombin-modified antithrombin, and also with antithrombin-thrombin complex. Similar results were obtained previously for the complexes between antithrombin and thrombin or Factor Xa (Wallgren et al., 1981). The result indicates that antithrombin is present in the antithrombin-trypsin complex in a form that is immunologically identical with modified antithrombin. i.e. proteolytically cleaved. The unavoidable presence of degradation products and some free modified antithrombin in the complex preparation analysed does not seriously challenge this conclusion.

\section{Discussion}

The present results show that most aspects of the reactions of antithrombin with the non-coagulation proteinase trypsin and with coagulation proteinases are similar or identical. Thus trypsin forms an equimolar complex with antithrombin with a dissociation rate constant comparable with that of the complexes between the inhibitor and coagulation proteinases. Moreover, in spite of the much wider catalytic specificity of trypsin, the same Arg-Ser bond, and only this bond, is cleaved in the modified antithrombin released from the antithrombin-trypsin complex as in the modified inhibitors from the complexes with coagulation proteinases. This supports the previous conclusion that this bond is the active-site bond of antithrombin (Jörnvall et al., 1979: Björk et al., 1982). In addition, a noncomplexed proteolytically modified form of antithrombin, highly similar to, or identical with, that produced by thrombin and Factor Xa, i.e. presumably cleaved at the active site (Jörnvall et al., 1979; Björk et al., 1982), is also formed in the antithrombin-trypsin reaction. Finally, the immunological analyses suggest that antithrombin exists in the same proteolytically cleaved state in the complex with trypsin as in the complexes with coagulation enzymes (Wallgren et al., 1981). Together, these results indicate a common mechanism for the inhibition of different serine proteinases by antithrombin, involving similar interactions with the same active-site region of the inhibitor.

The main differences between the inactivation of trypsin and coagulation proteinases by antithrombin are in the kinetics of the reactions. Under identical conditions in the absence of heparin, trypsin thus is inactivated by antithrombin about 20 times more rapidly than thrombin, which reacts faster with the inhibitor than either Factor $\mathrm{Xa}$ or Factor IXa (Kurachi et al., 1976; Jesty, 1978, 1979b). Moreover, heparin with high affinity for antithrombin has only a small effect on the antithrombin-trypsin reaction, analogous to its effect on the inhibition of kallikrein by antithrombin (Rosenberg et al., 1976). This is in contrast with the dramatic accelerating effect of the polysaccharide on the inhibition of coagulation proteinases of the intrinsic system (Rosenberg, 1977a,b; Barrowcliffe et al., 1978; Jordan et al., 1979, 1980). A possible reason for these differences is that, in the absence of heparin, the active-site region of antithrombin has a conformation such that this region is more easily accessible to the active site of trypsin than to that of coagulation proteinases, thereby allowing a faster reaction rate. This is reasonable because of the less restricted substrate specificity of trypsin. Moreover, this accessibility may not be significantly improved by the conformational change induced in antithrombin by the binding of heparin, in contrast with what appears to be the case in the reaction between the inhibitor and coagulation enzymes (Rosenberg \& Damus, 1973; Villanueva \& Danishefsky, 1977; Nordenman \& Björk, 1978; Jordan et al., 1980; Olson et al., 1981). Heparin thus does not appreciably affect the reaction rate. A further reason for the insignificant effect of heparin on the antithrombin-trypsin reaction may be the possibility that trypsin does not interact with heparin in the same manner as thrombin. Binding of thrombin to heparin has been shown to contribute to the increased rate of inactivation of this enzyme (Laurent et al., 1978; Jordan et al., 1980; Oosta et al., 1981; Holmer et al., 1981).

Antithrombin was found to inhibit trypsin with about the same rate constant as that reported for the inactivation of the enzyme by $\alpha_{1}$-proteinase inhibitor (Beatty et al., 1980). This suggests the possibility that antithrombin may serve as a general inhibitor of trypsin-like enzymes in plasma in the absence of heparin, albeit as an inhibitor of lesser importance than $\alpha_{1}$-proteinase inhibitor, because of the higher plasma concentration of the latter. In the presence of heparin, however, the specificity of antithrombin as an inhibitor of activated coagulation factors of the intrinsic system is markedly increased. The physiological significance of this effect is still uncertain, however, since endogenous heparin has not been conclusively demonstrated in blood (Jacobsson \& Lindahl, 1979).

This investigation was supported by research grants from the Swedish Medical Research Council (project nos. 4212 and 6213) and the Swedish Council for Forestry and Agricultural Research (project no. A5861). We 
sincerely thank Dr. Hans Jörnvall for the sequence analyses, and Ms. Elke Raub for excellent technical assistance.

\section{References}

Barrowcliffe, T. W., Johnson, E. A. \& Thomas, D. (1978) Br. Med. Bull. 34, 143-150

Beatty, K., Bieth, J. \& Travis, J. (1980) J. Biol. Chem. 255, 3931-3934

Björk, I. \& Fish, W. W. (1982) J. Biol. Chem. in the press

Björk, I., Danielsson, A., Fenton, J. W. II \& Jörnvall, H. (1981) FEBS Lett. 126, 257-260

Björk, I., Jackson, C. M., Jörnvall, H., Lavine, K. K., Nordling, K. \& Salsgiver, W. J. (1982) J. Biol. Chem. 257, 2406-2411

Carlström, A.-S., Liedén, K. \& Björk, I. (1977) Thromb. Res. 11, 785-797

Carrell, R. W., Boswell, D. R., Brennan, S. O. \& Owen, M. C. (1980) Biochem. Biophys. Res. Commun. 93, 399-402

Chang, J. Y., Brauer, D. \& Wittman-Liebold, B. (1978) FEBS Lett. 93, 205-214

Chase, T. \& Shaw, E. (1970) Methods Enzymol. 19, 20-27

Danielsson, A. \& Björk, I. (1980) FEBS Lett. 119, 241244

Danielsson, A. \& Björk, I. (1981) Biochem. J. 193, 427433

Einarsson, R. \& Andersson, L.-O. (1977) Biochim. Biophys. Acta 490, 104-111

Feinman, R. D. (1979) in The Physiological Inhibitors of Blood Coagulation and Fibrinolysis (Collen, D., Wiman, B. \& Verstraete, M., eds.), pp. 55-66, Elsevier/ North-Holland, Amsterdam and New York

Figarella, C., Negri, G. A. \& Guy, O. (1974) in Proteinase Inhibitors (Fritz, H., Tschesche, H., Green, L. J. \& Truscheit, E., eds.), pp. 213-222, Springer-Verlag, New York

Fish, W. W. \& Björk, I. (1979) Eur. J. Biochem. 101, 31-38

Fish, W. W., Orre, K. \& Björk, I. (1979a) FEBS Lett. 98, 103-106

Fish, W. W., Orre, K. \& Björk, I. (1979b) Eur. J. Biochem. 101, 39-44

Griffith, M. J. \& Lundblad, R. L. (1981) Biochemistry 20, $105-110$

Highsmith, R. F. \& Rosenberg, R. D. (1973) Nature (London) 246, 355-357

Holmer, E., Kurachi, K. \& Söderström, G. (1981) Biochem. J. 193, 395-400

Jacobsson, K. G. \& Lindahl, U. (1979) Thromb. Haemostasis 42, 84

Jesty, J. (1978) Arch. Biochem. Biophys. 185, 165-173

Jesty, J. (1979a) J. Biol. Chem. 254, 1044-1049

Jesty, J. (1979b) J. Biol. Chem. 254, 10044-10050

Jordan, R., Beeler, D. \& Rosenberg, R. D. (1979) J. Biol. Chem. 254, 2902-2913
Jordan, R. E., Oosta, G. M., Gardner, W. T. \& Rosenberg, R. D. (1980) J. Biol. Chem. 255, 1008110090

Jörnvall, H., Fish, W. W. \& Björk, I. (1979) FEBS Lett. 106, 358-362

Kurachi, K., Fujikawa, K., Schmer, G. \& Davie, E. W. (1976) Biochemistry 15, 373-377

Laurent, T. C., Tengblad, A., Thunberg, L., Höök, M. \& Lindahl, U. (1978) Biochem. J. 175. 691-701

Learned, L. A., Bloom, J. W. \& Hunter, M. J. (1976) Thromb. Res. 8, 99-109

Longas, M. O. \& Finlay, T. H. (1980) Biochem. J. 189, 481-489

Lundblad, R. L., Uhteg, L. C., Vogel, C. N., Kingdon, H. S. \& Mann, K. G. (1975) Biochem. Biophys. Res. Commun. 66, 482-489

Mahoney, W. C., Kurachi, K. \& Hermodson, M. A. (1980) Eur. J. Biochem. 105, 545-552

Miller-Andersson, M., Borg, H. \& Andersson, L.-O. (1974) Thromb. Res. 5, 439-452

Nordenman, B. \& Björk, I. (1978) Biochemistry 17, 3339-3344

Nordenman, B., Nyström, C. \& Björk, I. (1977) Eur. J. Biochem. 78, 195-203

Olson, S. T., Srinivasan, K. R., Björk, I. \& Shore, J. D. (1981) J. Biol. Chem. 256, 11073-1 1079

Oosta, G. M., Gardner, W. T., Beeler, D. L. \& Rosenberg, R. D. (1981) Proc. Natl. Acad. Sci. U.S.A. 78, 829833

Owen, W. G., Esmon, C. T. \& Jackson, C. M. (1974) J. Biol Chem. 249, 594-605

Petersen, T. E., Dudek-Wosciechowska, G., SottrupJensen, L. \& Magnusson, S. (1979) in The Physiological Inhibitors of Blood Coagulation and Fibrinolysis (Collen, D., Wiman, B. \& Verstraete, M., eds.), pp. 43-54, Elsevier/North-Holland, Amsterdam and New York

Robinson, N. C., Ross, W. T., Neurath, H. \& Walsh, K. A. (1971) Biochemistry 10, 2743-2747

Rosenberg, R. D. (1977a) Fed. Proc. Fed. Am. Soc. Exp. Biol. 36, 10-18

Rosenberg, R. D. (1977b) Semin. Hematol. 14, 427-440

Rosenberg, R. D. \& Damus, P. S. (1973) J. Biol. Chem. 248, 6490-6505

Rosenberg, R. D., Lahiri, B., Bagdasarian, A., Mitchell, B., Talamo, R. C. \& Coleman, R. W. (1976) Arch. Biochem. Biophys. 175, 737-747

Villanueva, G. B. \& Danishefsky, I. (1977) Biochem. Biophys. Res. Commun. 74, 803-809

von Bahr-Lindström, H., Hempel, J. \& Jörnvall, H. (1982) J. Protein Chem. in the press

Wallgren, P., Nordling, K. \& Björk, I. (1981) Eur. J. Biochem. 116, 493-496

Weber, K. \& Osborn, M. (1969) J. Biol. Chem. 244, 4406-4412

Yung, B. Y. \& Trowbridge, C. G. (1975) Biochem. Biophys. Res. Commun. 65, 927-930 